\title{
Narratives of focal brain injured individuals: A macro-level analysis
}

\author{
Ayşenur Karaduman $^{\mathrm{a}, \mathrm{b}}$, Tilbe Göksun ${ }^{\mathrm{a}, *}$, Anjan Chatterjee \\ ${ }^{a}$ Koç University, Istanbul, Turkey \\ b Bilkent University, Ankara, Turkey \\ ${ }^{\mathrm{c}}$ University of Pennsylvania, Philadelphia, PA, USA
}

\section{A R T I C L E I N F O}

\section{Keywords:}

Narrative

Focal brain injury

Narrative complexity

Narrative evaluation

\begin{abstract}
A B S T R A C T
Focal brain injury can have detrimental effects on the pragmatics of communication. This study examined narrative production by unilateral brain damaged people $(n=36)$ and healthy controls and focused on the complexity (content and coherence) and the evaluative aspect of their narratives to test the general hypothesis that the left hemisphere is biased to process microlinguistic information and the right hemisphere is biased to process macrolinguistic information. We found that people with left hemisphere damage's (LHD) narratives were less likely to maintain the overall theme of the story and produced fewer evaluative comments in their narratives. These deficits correlated with their performances on microlinguistic linguistic tasks. People with the right hemisphere damage (RHD) seemed to be preserved in expressing narrative complexity and evaluations as a group. Yet, single case analyses revealed that particular regions in the right hemisphere such as damage to the dorsolateral prefrontal cortex (DLPFC), the anterior and superior temporal gyrus, the middle temporal gyrus, and the supramarginal gyrus lead to problems in creating narratives. Our findings demonstrate that both hemispheres are necessary to produce competent narrative production. LHD people's poor production is related to their microlinguistic language problems whereas RHD people's impaired abilities can be associated with planning and working memory abilities required to relate events in a narrative.
\end{abstract}

\section{Introduction}

A narrative develops around characters and events, and has a superstructure that includes establishing the setting of events, relating actions, and resolving themes (Ulatowska et al., 1990). Speakers express temporal progression, establish and maintain references, and emphasize specific events over others in their narrations. Studying narrative discourse provides rich information that enables us to examine speakers' communicative competence and their ability to use language in context (for a recent review, see Linnik et al., 2016). This investigation examined the relationship among cognition, the organization of human knowledge, and language production.

Broadly, two levels of analyses are used to study narrative production: (1) a within utterance or a microlinguistic level that mainly focuses on lexical and grammatical processing that contribute to intrasentential structure, and (2) a between-utterance or a macrolinguistic level that focuses on pragmatic and discourse-level processing, responsible for intersentential organization (Andreetta et al., 2012; Glosser and Deser, 1990; Jakobson, 1980; Kintsch, 1994). This study examines narrative production of both people with left hemisphere damage (LHD) and people with right hemisphere damage (RHD) to test the hypothesis that the left hemisphere is biased to process microlinguistic elements and the right hemisphere is biased to process macrolingustic information.

Even though macrolinguistic level narrative production has been studied previously (Andreetta et al., 2012; Berko-Gleason et al., 1980; Bloom et al., 1992; Coelho et al., 2012; Davis et al., 1997; Joanette et al., 1986; Marini et al., 2005; Ulatowska et al., 1981, 1983), the current study moves beyond the classical analyses. We address three questions: (1) How do people with LHD and RHD differ in their narrative complexity (indicated by content and coherence) and the richness of expression (e.g., cognitive inferences about the motivation behind protagonists' actions or references to affective states)? (2) What, if any, is the relationship between microlinguistic and macrolinguistic competence? (3) What brain lesions relate to impairments in narrative complexity and the evaluation?

In the following sections, we first briefly review the current state of the field on microlinguistic language production of unilateral brain damaged people. Then, we focus on macrolinguistic language production and present the current study.

\footnotetext{
* Correspondence to: Department of Psychology, Koç University, Rumelifeneri Yolu, Sariyer 34450, Istanbul, Turkey.

E-mail address: tgoksun@ku.edu.tr (T. Göksun).
} 


\subsection{Microlinguistic level language production}

Microlinguistic functions of language production usually depend on the integrity of specialized neural systems within the left hemisphere (Glosser and Deser, 1990). Unsurprisingly, people with LHD can impair verbal communication at almost all intrasentential linguistic levels (phonetic, semantic, and syntactic) (Herrmann et al., 1989). For example, people with LHD utter fewer motion sentences, talk with lower mean length of utterance, produce fewer types of verbs and prepositions than controls (Göksun et al., 2015). They produce less complex language, demonstrate word-finding difficulties (Dressler and Pleh, 1988; Larfeuil and Dorze, 1997), and the words they produce are often indefinite such as "get" as compared to people with RHD (Ulatowska et al., 1981). However, previous reports on the LHD-aphasic people's ability to use linguistic devices that help make the narrative cohesive (e.g., personal pronouns, demonstrative pronouns, conjunctions) are conflicting; some find deficits (Ulatowska et al., 1981), whereas others do not (Bloom, Borod, Santschi-Haywood et al., 1996; Glosser and Deser, 1990).

While the role of the left hemisphere in processing the microlinguistic level is well established, the right hemisphere's contribution remains uncertain. Several studies report that people with RHD perform adequately with respect to lexical selection and syntactic complexity (Glosser, 1993; Glosser et al., 1992; Rivers and Love, 1980). Others report reduced syntactic complexity (Joanette et al., 1986; Sheratt and Bryan, 2012) and elaborated, imprecise, and repetitive speech (Sheratt and Bryan, 2012). Mixed results have also been reported for the correct use of cohesive markers (e.g., Marini et al., 2005; Uryase et al., 1991). The intrasentential level of content relevance during discourse production can be reduced in people with RHD, indicating low level of informativeness for their stories (Bartels-Tobin and Hickley, 2005; Marini et al., 2005). This reduction may indicate problems in global levels of discourse, which is reviewed as macro-linguistic level problems in the next section.

Overall, people with LHD clearly have microlinguistic deficits, whereas reports for people with RHD are inconsistent.

\subsection{Macrolinguistic level language production}

Macrolinguistic language production emphasizes pragmatic and discourse level analyses, focusing on different aspects such as content and coherence (narrative complexity) and evaluations. The content of a narrative determines if individuals successfully communicate the critical aspects of a story using coherent thematic units (for review see Mar, 2004). A narrative with a thematically coherent plotline includes three components: Plot onset referring to an initiating event, plot unfolding referring to progressing events in the story, and plot resolution referring to arrival at an outcome (Berman and Slobin, 1994).

A narrative is made richer by including evaluative comments, which can suspend describing the sequence of events (Bamberg and DamradFrye, 1991; Labov and Waletzky, 1967). In a well-constructed narrative, the narrator comments on the meaning or the significance of the events using particular evaluative devices. These devices might reflect the narrator's perspective on the characters and their activities such as inferring the motivations or affective states/behaviors of the character. The narrator can also give his/her subjective opinions on the events or use expressions or exclamations to maintain audience interest (see Appendix B for the details of the evaluative devices) (Bamberg and Damrad-Fyre, 1991, Küntay and Nakamura, 2004, Labov and Waletzky, 1967; Reilly et al., 2004). Story actions and resolution are enriched with these evaluative devices (Freedman-Stern, Ulatowska, Baker, and DeLacoste, 1984).

Neuroimaging studies suggest that bilateral medial and lateral frontal and anterior temporal regions and the precuneus are involved in establishing narrative coherence (Fletcher et al., 1995; Ferstl et al.,
2008; Xu et al., 2005). Troiani and colleagues (2008) suggest that narrative production depends in part on a network involving frontal and temporal brain regions. In particular, narrative production activates the inferior frontal cortex bilaterally, and the left dorsal inferofrontal and left lateral temporal-parietal regions (see also Braun et al., 2001; Mar, 2004).

Neuropsychological evidence about narrative production mainly comes from studies with people with aphasia after left brain injury (Andreetta et al., 2012; Christiansen, 1995; Berko- Gleason et al., 1980; Bloom et al., 1992; Huber and Gleber, 1982; Mar, 2004; Marini et al., 2005, 2011a; Nicholas and Brookshire, 1993; Ulatowska et al., 1981, 1983) and people with right brain injury (e.g., Bartels-Tobin and Hickley, 2005; Joanette et al., 1986; Mar, 2004; Marini, 2012; Marini et al., 2011b, Sherratt and Bryan, 2012). As mentioned earlier, people with LHD have more problems at a microlinguistic level compared to people with RHD, in whom the performances for macro-linguistic processes are mixed. Some report simplified content as indicated by the production of fewer episodes (Berko- Gleason et al., 1980; Bloom et al., 1992; Ulatowska et al., 1981, 1983). Individuals with left dorsolateral prefrontal cortex (DLPFC) lesions can omit critical story components and fail to establish global coherence by relating the meaning or content of an utterance to the general topic of the story (Andreetta et al., 2012; Coelho et al., 2012; Christiansen, 1995).

In contrast, others report that LHD-aphasic patients devote normal proportions of their narratives to relevant structural elements, and maintain their order. Story grammar is also relatively preserved (Ulatowska et al., 1981). Counting coherence errors of LHD-nonaphasic people such as absence of a referent, semantic shifts or tangential utterances, Marini and colleagues (2005) revealed preserved coherent organization for LHD-nonaphasic people. They also preserve informativeness as indicated by their use of adequate number of thematic units.

Very few studies assess patients' use of evaluative utterances in narrative. LHD-aphasic patients produce fewer clauses containing evaluative expressions compared to healthy controls (Ulatowska et al., 1981, 1983). This reduction may not affect the overall plot structure, since evaluation has a secondary role among other narrative structure elements such as setting or resolution, but evaluation contributes to the narrative's richness in real world communication.

Narrative production deficits in people with RHD include problems in presenting the order of themes, staying on a topic or using nonverbal cues (Bartels-Tobin and Hinckley, 2005; Davis et al., 1997; Joanette et al., 1986; Marini et al., 2005; Sherratt and Bryan, 2012, for a review see Mar, 2004). Using sequential visual stimuli or videos, studies show that RHD people's narratives lack critical story elements that are essential to its telling, which results in less informative discourse than those of healthy controls (Bartels-Tobin and Hickley, 2005; Bloom et al., 1992; Joanette et al., 1986; Marini et al., 2005; Rivers and Love, 1980; Uryase, Duffy, and Liles, 1991). In addition, people with RHD have problems producing complete stories (i.e. stories with an obvious beginning and end, integrating information from each sequential picture) compared to controls (Rivers and Love, 1980). Similarly, the completeness of episodes and story grammar elements such as setting and initiating event can be missing (Uryase et al., 1991).

On the coherence of narratives, Davis and colleagues (1997) found that people with RHD produce less logical connections between actions in a narrative than controls, indicating deficiency in establishing logical coherence. Based on the analyses of semantic shifts, absence of referent or tangential utterances, Marini and colleagues (2005) found that people with RHD have problems with communicating the relevance and quantity of information. They often insert additional and excessive details, insufficient content or do not include appropriate information in their narratives (Sheratt and Bryan, 2012).

Several explanations are proposed for RHD people's problems in narratives. Some focus on factors such as stimulus processing and task demands as people with RHD tend to display visuospatial and/or visuoperceptive deficits (Hécaen and Albert, 1978) (Rivers and Love, 
1980). Marini and colleagues (2005) concluded that people with RHD have problems in organizing informational content and in retrieving a general story schema from pictorial but not from linguistic information (but see Delis et al., 1983). Another possibility that may contribute to the RHD people's discourse deficits is the inability to capture emotional nuances and interpret the emotional importance of pictured scenes (e.g., Cicone et al., 1980; DeKosky et al., 1980; Moscovitch, 1983). Consistent with this interpretation, Bloom and colleagues (1992) reported specific reduction in the production of emotional content relative to neutral/procedural and visual-spatial content, suggesting a distinctive role for the right hemisphere in verbally expressing emotions.

\subsection{The present study}

Despite accumulating evidence on macrolinguistic level language production abilities for both people with LHD and RHD, results are not conclusive for either group (e.g., Delis et al., 1983; Marini et al., 2005). In addition, research on aphasia has mainly focused on the production of relatively concrete and factual information while the way the narrator conveys her particular stance or viewpoint on this information and how she engages the audience is understudied (Armstrong and Ulatowska, 2007). Only a few studies examine the evaluative aspect of narration in LHD-aphasic people (e.g., Ulatowska, 1981; 1983) or people with RHD (but see Bloom et al., 1992; Cimino et al., 1991). Finally, these studies consider left and right brain injured people as whole groups, and do not consider specific areas of vulnerability within hemisphere.

In this study, we will investigate how narrative complexity and richness can be affected by unilateral brain injury. Beyond laterality, we asked whether specific lesion locations are associated with impairments in narrative complexity and the evaluation of narratives and whether microlinguistic and macrolinguistic deficits are related.

We predicted that people with RHD would be less likely to include basic story components into narratives than control participants. LHD people's narratives may be impaired. However, compared to RHD people's narratives, they would not have reduced informative components as a primary deficit.

LHD people's use of evaluative devices would be impaired based on previous reports. We also predicted that the use of affective states and behaviors as a specific subgroup of evaluative devices might differentiate the RHD group from controls because of impairments in extracting emotional information from visual stimuli (e.g., Bloom et al., 1992).

Finally, to investigate individual cases who could have impairments in expressing narrative complexity and evaluation, we applied "Bayesian analysis for a simple difference" (Crawford et al., 2010). This case analytic method applies Bayesian Monte Carlo methods to determine whether a subjects' performance is an observation from the control population, as stated by the null hypothesis. If the test indicates that the patient's score is significantly below the average scores of control participants, the null hypothesis can be rejected (Ianni et al., 2014). For the unilateral brain damaged participants who perform abnormally on a given dependent variable, we report lesion overlays to characterize specific lesions associated with poor performance.

\section{Material and methods}

\subsection{Participants}

Participants were enrolled from the Focal Lesion Subject Database at the University of Pennsylvania (Fellows et al., 2008). Eighteen people with LHD and 18 people with RHD were included in the study. They were not chosen based on specific lesion locations or behavioral criteria. Fig. 1 displays lesion overlap maps of participants. The patients did not have a history of other neurological disorders, psychiatric disorders, or substance abuse. People with LHD ranged in age from 37 to 79 ( $M=64.28, S D=11.75,10$ females $)$ and people with RHD ranged in age from 45 to 87 ( $M=63.33, S D=12.4,12$ females). The people with LHD and RHD had an average of $13.56(S D=2.01)$ and 15 (SD $=3.33$ ) years of education, respectively. People with LHD and RHD did not differ in lesion size, $p>.05$. Thirteen age-matched (range: 38-77, $M=60.85, S D=11.05$, 9 females) older adults served as a healthy control group. They had an average of $16(S D=2.04)$ years of education. Education level was significantly different among groups, $F(2,46)=3.49, p=.04, \eta^{2}=.13$. People with LHD $(M=13.56, S D$ $=2.01)$ had fewer years of education than the controls $(M=16, S D$ $=2.12$ ). All RHD and control participants were right-handed and one LHD participant was left-handed. All participants were native Englishspeakers. We limited our participants to individuals with a minimum of 10 years of education. All participants provided written informed consent in accordance with the policies of the University of Pennsylvania's Institutional Review Board. Participants received $\$ 15 / \mathrm{h}$ for volunteering their time.

\subsection{Materials and procedure}

\subsubsection{Neuropsychological tasks}

People with LHD and RHD were administered the language comprehension and language production subtests of the Western Aphasia Battery (WAB; Kertesz, 1982). They were also administered the Object and Action Naming Battery (OANB; Druks, 2000). In this task, participants named 50 pictures of actions and 81 pictures of objects. The neuropsychological tests were administered on a different session either before or after the narrative task.

\subsubsection{Narrative task}

The participants were presented with the 24-page wordless children's picture book, Frog, Where Are You? (Mayer, 1969) and asked to tell a story to the experimenter. The story is about a boy and his dog, searching for their frog. While they are searching for the frog, the boy and the dog have a series of adventures such as encountering a groundhog, a hive of bees, an owl, and a deer. At the end of the story, they find the lost frog with a female frog and several baby frogs. The boy and the dog take one of the babies as their new pet frog while waving goodbye to the frog family. The book contains no words and has been used to elicit narratives in more than 70 languages and in diverse populations including patients (e.g., Ash et al., 2006; Berman and Slobin, 1994; Reilly et al., 1998, 2004). In addition to the series of temporally sequenced complex events with sketched drawings, the book requires narrators to make inferences about the characters' relationships, thoughts, feelings, and motivations throughout the story, providing appropriate stimuli for the investigation of evaluative language (Küntay and Nakamura, 2004; Reilly et al., 2004).

Before beginning to tell the story, participants looked through and familiarized themselves with the book. When ready, they started from the beginning and described the story page by page. Sessions were videotaped for further transcriptions of speech. The neuropsychological tasks were administered on a different testing session either before or after the experimental task.

\subsection{Coding}

Narratives were transcribed word by word by native English speakers. First, event chunks were coded for general features of language production: the number of utterances, the number of words, mean length of utterance (MLU), and the number of nouns and verbs. An utterance was defined as a T-unit that consisted of an independent clause and all clauses or phrases on it (Hunt, 1965). When two independent clauses conjoined by the connective "and", they were counted as two utterances. MLU was defined as total number of words per utterance (Marini et al., 2008). Number of words included all 


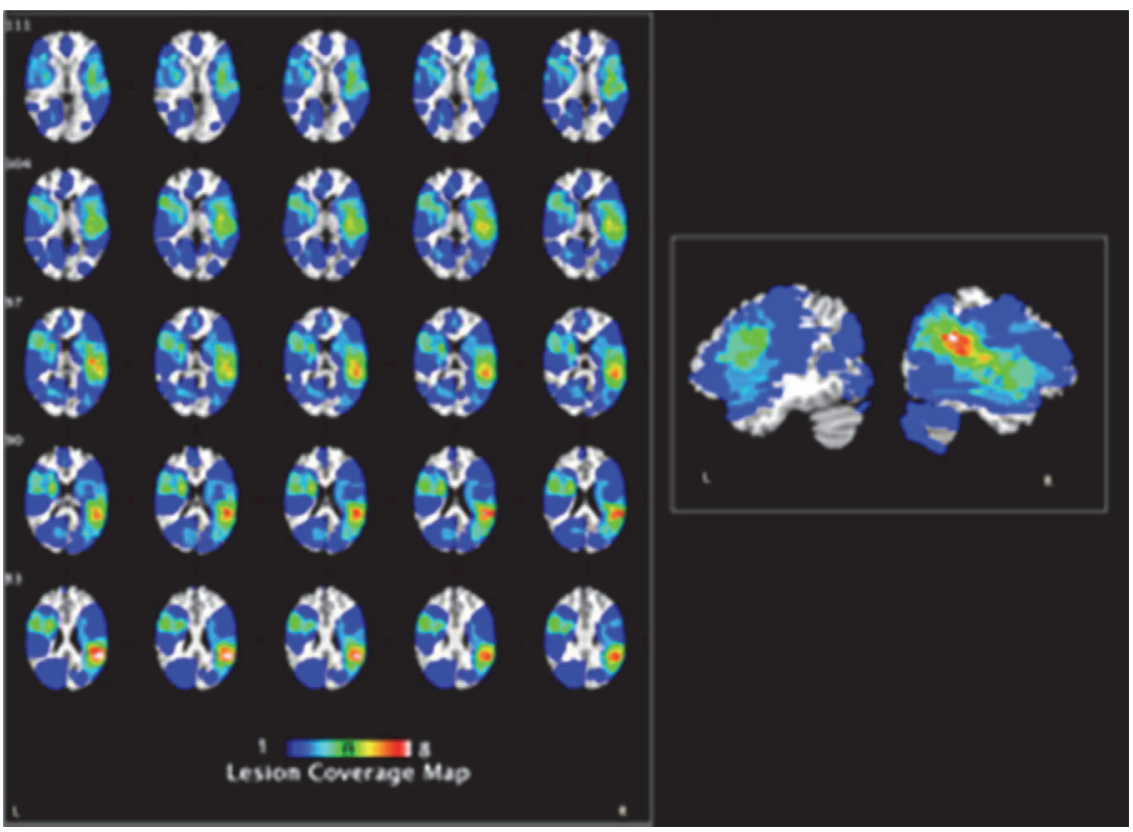

Fig. 1. Coverage map indicating the lesion locations for all participants with brain damage. The colored scale represents the number of lesions for each pixel.

complete words (repetitions were included). All nouns and verbs (inflected verbs, infinitives, and participles) were also counted (see Ash et al., 2006 for details of speech coding).

Second, the transcriptions were coded for the narrative complexity based on the criteria discussed in Berman and Slobin (1994), Köksal (2011). Definition and examples of coding for narrative complexity is provided in Appendix A. The narratives were coded for the three main plot components including plot onset, plot unfolding and plot resolution:

1) The plot onset component was scored based on the presence of the following sub-components: The precedent event (e.g., the boy wakes up), temporal location (in the morning/evening), characters (the boy, the dog, the frog), main characters' finding out that something has happened to the frog (e.g., the boy noticed that the frog had gone missing), inference about the frog's disappearance (e.g., the frog escaped the fishbowl) and the response of the protagonist (e.g., the boy was shocked). Thus, one can obtain a score from 0 to 8 .

2) The plot unfolding component included the following sub-components: looking for the lost frog in the home, interaction with bees, with gopher, with owl, with deer and falling down into the lake. The narration of these subcomponents determined the score that ranged from 0 to 6 .

3) The plot resolution component was scored based on the reference to finding the lost frog by the protagonists and the presence of this component received 1 point.

In addition to these three plot components, the narratives were also coded for the search theme to examine the degree to which the subjects understood the motivation for the boy's actions and the overall theme of the story. We coded 1) whether the subject explicitly mentioned that the frog was missing and that the boy was searching for it (the scores ranged from 0 to 2: 1 point for mentioning each of these two aspects), and 2) whether the search theme was reiterated later in the story: The subjects received 0 points for no additional mention, 1 point for one or two additional mentions and 2 points for multiple additional mentions. This analysis of reiteration of the search theme indicated the extent to which the subjects understood the boy's continuing behavior (Reilly et al., 1998).

Third, to examine the extent to which subjects evaluated the content of their narratives, we coded the use of specific evaluative devices (cognitive inferences, social engagement devices, references to affective states or behaviors, enrichment expressions, hedges and evaluative remarks) by adapting and combining the schemes used by Reilly and colleagues (2004), Küntay and Nakamura (2004), and Bamberg and Damrad-Fyre (1991). Appendix B presents explanations of these categories and examples from our data. A total evaluation score was obtained by summing across all of the scores from subcategories for each subject.

In addition, an evaluative diversity score was obtained, indicating the range of evaluation subcategories produced in the narrative by assigning 1 to used subcategories and 0 to the unused categories. Thus, the possible score for evaluative diversity ranged from 0 to 5 .

\subsection{Reliability}

Two independent transcribers checked all the transcriptions. To establish reliability, a second person coded randomly selected narratives of 9 out of 36 participants with unilateral brain damage (25\%) and 5 healthy controls out of $13(38.5 \%)$ for both narrative complexity and evaluation measures. For narrative complexity, agreement between coders was $98 \%$ and for the evaluative devices it was $95 \%$. Agreement for the subcategories of evaluative devices was as follows: Cognitive inferences: $100 \%$, social engagement: $90 \%$, references to affective states and behaviors: 99\%, enrichment expressions: 98\%, hedges $99 \%$, evaluative remarks $94 \%$.

\section{Results}

\subsection{Neuropsychological analyses}

Most people with LHD and RHD in this study were not severely impaired (only 6 participants were categorized as having anomic aphasia and 1 participant was categorized as having Wernike's aphasia based on WAB classification. These participants were all in the LHD group). The WAB scores were lower for the people with LHD compared to the people with RHD, $F(1,29)=6.802, p=.014, \eta^{2}=.19$ $\left(\mathrm{M}_{\mathrm{LHD}}=91.75\right.$ and $\left.\mathrm{M}_{\mathrm{RHD}}=97.94\right)$. The groups did not differ significantly in terms of naming objects and actions, $F(1,27)=2.007$, $p=.168, \eta^{2}=.07$ and $F(1,28)=1.428, p=.242, \eta^{2}=.05$, respectively (see Table 1, for CIs see Table 6) (Tables 2, 3, 4, 5 and 6). 
Table 1

Demographic and neuropsychological data of people with LHD and RHD.

\begin{tabular}{|c|c|c|c|c|c|c|c|c|c|c|c|}
\hline Patient & Gender & Age & $\begin{array}{l}\text { Education } \\
\text { (years) }\end{array}$ & $\begin{array}{l}\text { Lesion } \\
\text { Side }\end{array}$ & Location & $\begin{array}{l}\text { Lesion Size } \\
\text { (\# of voxels) }\end{array}$ & Cause & Chronicity & $\begin{array}{l}\text { WAB } \\
\text { (AQ) }\end{array}$ & $\begin{array}{l}\text { OANB } \\
\text { (Action) }\end{array}$ & $\begin{array}{l}\text { OANB } \\
\text { (Object) }\end{array}$ \\
\hline LT_85 & $\mathrm{F}$ & 63 & 15 & $\mathrm{~L}$ & I & 13079 & Stroke & 177 & 98.8 & 100 & 98.8 \\
\hline CD_141 & $\mathrm{F}$ & 52 & 16 & $\mathrm{~L}$ & $\mathrm{~T}$ & 21605 & Stroke & 143 & 98.8 & 100 & 96 \\
\hline KG_215 & M & 61 & 14 & $\mathrm{~L}$ & $\mathrm{~F}$ & 17422 & Stroke & 145 & 94.4 & 96 & 93.8 \\
\hline TO_221 & $\mathrm{F}$ & 77 & 13 & $\mathrm{~L}$ & $\mathrm{O}$ & 5886 & Stroke & 160 & 100 & 100 & 100 \\
\hline BC_236 & M & 65 & 18 & $\mathrm{~L}$ & FP & 155982 & Stroke & 210 & 80.8 & 88 & 94 \\
\hline XK_342 & $\mathrm{F}$ & 57 & 12 & $\mathrm{~L}$ & от & 42144 & Stroke & 125 & 91.4 & 94 & 93 \\
\hline TD_360 & M & 58 & 12 & $\mathrm{~L}$ & T BG & 38063 & Stroke & 118 & 65.3 & 52 & 28 \\
\hline IG_363 & M & 74 & 16 & $\mathrm{~L}$ & $\mathrm{~F}$ & 16845 & Stroke & 117 & 91.4 & 96 & 95 \\
\hline KD_493 & M & 68 & 14 & $\mathrm{~L}$ & $\mathrm{~T}$ & 22404 & Aneurysm & 101 & 92.1 & 98 & 95 \\
\hline DR_529 & $\mathrm{F}$ & 66 & 12 & $\mathrm{~L}$ & PA F & 8969 & Stroke & 100 & 94.9 & 94 & 90.1 \\
\hline DR_565 & $\mathrm{F}$ & 53 & 12 & $\mathrm{~L}$ & PA F & 14517 & Aneurysm & 103 & 99.8 & 98 & 97.5 \\
\hline MC_577 & $\mathrm{F}$ & 79 & 11 & $\mathrm{~L}$ & $\mathrm{C}$ & 4191 & Stroke & 50 & 85.3 & 82 & 79 \\
\hline NS_604 & $\mathrm{F}$ & 37 & 12 & $\mathrm{~L}$ & $\mathrm{PO}$ & 79231 & AVM & 113 & 100 & 100 & 98 \\
\hline UD_618 & M & 77 & 15 & $\mathrm{~L}$ & $\mathrm{~F}$ & 48743 & Stroke & 47 & 89.4 & 76 & 85 \\
\hline KM_642 & M & 77 & 12 & $\mathrm{~L}$ & $\mathrm{P}$ & 7996 & Stroke & 109 & 96.8 & 94 & 98 \\
\hline MR_644 & $\mathrm{F}$ & 74 & 12 & $\mathrm{~L}$ & $\mathrm{C}$ & - & Stroke & - & - & - & - \\
\hline CC_749 & $\mathrm{F}$ & 71 & 12 & $\mathrm{~L}$ & $\mathrm{P}$ & 34266 & Stroke & 50 & 88.8 & - & - \\
\hline FC_83 & M & 70 & 12 & $\mathrm{R}$ & FTP & 8040 & Stroke & 169 & 99.8 & 96 & 98 \\
\hline MB_101 & $\mathrm{F}$ & 58 & 18 & $\mathrm{R}$ & T BG & 10543 & Stroke & 426 & 98.4 & 98 & 98 \\
\hline NC_112 & $\mathrm{F}$ & 48 & 16 & $\mathrm{R}$ & $\mathrm{O}$ & 4733 & Stroke & 178 & 100 & 98 & - \\
\hline HX_252 & M & 77 & 12 & $\mathrm{R}$ & MCA & - & Stroke & - & 94.6 & 78 & 85 \\
\hline RT_309 & $\mathrm{F}$ & 66 & 21 & $\mathrm{R}$ & $\mathrm{T}$ & 79691 & Hematoma & 128 & - & - & - \\
\hline DF_316 & $\mathrm{F}$ & 87 & 12 & $\mathrm{R}$ & $\mathrm{P}$ & 2981 & Stroke & 126 & 97.1 & 88 & 93 \\
\hline DC_392 & M & 56 & 10 & $\mathrm{R}$ & PT & 39068 & Stroke & 108 & 97.6 & 98 & 95 \\
\hline DX_444 & $\mathrm{F}$ & 80 & 12 & $\mathrm{R}$ & $\mathrm{PT}$ & 41172 & Stroke & 106 & 95.5 & 94 & 93 \\
\hline TS_474 & $\mathrm{F}$ & 51 & 11 & $\mathrm{R}$ & $\mathrm{P}$ & 22208 & Stroke & 100 & 95.1 & 98 & 95 \\
\hline UD_550 & $\mathrm{F}$ & 47 & 16 & $\mathrm{R}$ & $\mathrm{C}$ & - & Stroke & - & - & - & - \\
\hline NS_569 & $\mathrm{F}$ & 72 & 18 & $\mathrm{R}$ & FT BG & 37366 & Stroke & 77 & 100 & 100 & 99 \\
\hline DG_592 & $\mathrm{F}$ & 45 & 12 & $\mathrm{R}$ & $\mathrm{PT}$ & 130552 & Stroke & 127 & 97.8 & 98 & 98 \\
\hline KG_593 & $\mathrm{F}$ & 49 & 12 & $\mathrm{R}$ & FTP BG & 170128 & Stroke & 58 & 100 & 90 & 95 \\
\hline KS_605 & M & 63 & 18 & $\mathrm{R}$ & C & 23217 & Stroke & 76 & 98.8 & 100 & 100 \\
\hline ND_640 & $\mathrm{F}$ & 70 & 18 & $\mathrm{R}$ & PT & 64603 & Stroke & 54 & 96.8 & 100 & 100 \\
\hline CS_657 & M & 75 & 18 & $\mathrm{R}$ & $\mathrm{PO}$ & 33568 & Stroke & 43 & 99.2 & 98 & 100 \\
\hline KN_675 & M & 64 & 18 & $\mathrm{R}$ & FT & 23779 & Stroke & 32 & - & - & - \\
\hline MN_738 & $\mathrm{F}$ & 62 & 16 & $\mathrm{R}$ & $\mathrm{C}$ & 32154 & Stroke & 25 & 98.4 & 100 & 100 \\
\hline DD_755 & $\mathrm{F}$ & 48 & 16 & $\mathrm{~L}$ & $\mathrm{C}$ & - & Stroke & - & - & - & - \\
\hline
\end{tabular}

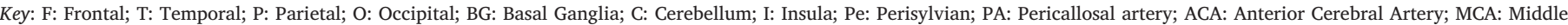

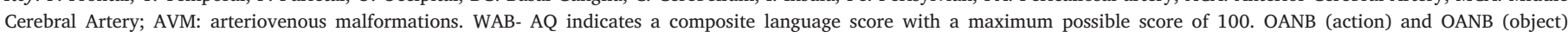
demonstrate knowledge of verbs and nouns with a maximum possible score of 100 .

\subsection{Narrative length measures}

No main effect of group was found for the total number of utterances they produced $\left(F(2,46)=.557, p=.577, \eta^{2}=.02\right)$ or the number of words, $\left(F(2,46)=1.814, p=.174, \eta^{2}=.07\right)$, verbs, $(F(2,46)$ $\left.=2.697, p=.078, \eta^{2}=.11\right)$, and nouns they used, $(F(2,46)=1.790$, $p=.178, \eta^{2}=.07$ ) (for CIs see Table 6). However, the results revealed a significant difference in the mean length of utterance (MLU) score among groups, $F(2,46)=7.175, p=.002, \eta^{2}=.24$. Bonferroni $t$-tests showed that the LHD people's MLU scores $(M=8.66, S D=.88)$ were significantly lower than the controls' $(M=10.42, S D=1.55)(p=.001)$. For people with LHD and RHD, the production of nouns in narratives positively correlated with Object and Action Naming Battery's object scores $(r=.438, p=.017$ ) (see Table 2).

\subsection{The narrative complexity}

A univariate ANOVA indicated a main effect of group for narrative complexity, $F(2,46)=3.555, p=.037, \eta^{2}=.13$. As shown in Fig. 2 , the LHD people's narratives included significantly fewer story components $(M=12.56, S D=4.66)$ than the controls' $(M=16.31, S D=1.25)$, (Bonferroni, $p=.032$ ). After controlling for education, narrative complexity did not differ significantly among groups, $F(2,45)=2.063$, $p=.139, \eta^{2}=.08$. When the scores obtained from each plot component (plot onset, plot unfolding, and resolution) were analyzed separately, the results showed no differences among groups (plot onset: $F(2,46)$ $=1.977, p=.15, \eta^{2}=.08$, plot unfolding: $F(2,46)=3.146, p=.052$, $\eta^{2}=.12$, and resolution: $F(2,46)=2.743, p=.075, \eta^{2}=.11$, respectively) (for CIs see Table 6). However, a significant difference among groups was found in establishing and maintaining the story's search theme, $F(2,46)=4.082, p=.023, \eta^{2}=.15$. The people with LHD established and maintained the story's search theme $(M=2.39, S D$ $=.31)$ significantly less often than the controls $(M=3.77, S D=.37)$ (Bonferroni, $p=.02$ ). Yet, when we looked at each score alone (establishing the initial mention of the search theme and maintaining the theme), no difference was revealed for the initial mention of the search theme among groups, $F(2,46)=2.110, p=.133, \eta^{2}=.08$. But a main effect of group was found for maintaining the search theme, $F(2,46)$ $=4.836, p=.012, \eta^{2}=.17$. In particular, the people with LHD reiterated the search theme less often $(M=1, S D=.18)$ than the controls ( $M$ $=1.85, S D=.21$ ), (Bonferroni, $p=.01$ ).

The narrative complexity was also tested at the level of individual patient using Bayesian single-case statistics. Results revealed that 7 people with LHD (out of 18) and 4 people with RHD (out of 18) were impaired in including story components in their narratives compared to the controls, $p<.01$ (see Table 3 ). We then constructed a lesion overlap for these participants who were significantly impaired. As shown in Fig. 3, these participants' lesions maximally overlapped in the right frontal lobe including the dorsolateral prefrontal cortex (DLPFC), both the anterior and superior temporal gyrus, the middle temporal gyrus, and the supramarginal gyrus; in the left hemisphere the middle, inferior and superior frontal gyrus, and left insula.

The narrative complexity score correlated positively with all the neuropsychological test scores; WAB $(r=.582, p=.001)$, Object and 
Table 2

Correlations between measures.

\begin{tabular}{|c|c|c|c|c|c|c|c|c|c|c|c|c|c|}
\hline & & 2 & 3 & 4 & 5 & 6 & 7 & 8 & 9 & 10 & 11 & 12 & 13 \\
\hline \multirow[t]{4}{*}{ 1. WAB } & $r$ & $.839^{\mathrm{b}}$ & $.874^{\mathrm{b}}$ & -.125 & .065 & .131 & .322 & .152 & .191 & $.582^{\mathrm{b}}$ & $.523^{\mathrm{b}}$ & $.386^{\mathrm{a}}$ & .159 \\
\hline & $N$ & 30 & 29 & 30 & 31 & 31 & 31 & 31 & 31 & 31 & 31 & 31 & 31 \\
\hline & 95\% C. I. Lower & .466 & .524 & -.598 & -.462 & -.437 & -.391 & -.333 & -.134 & .084 & .083 & .077 & -.187 \\
\hline & Upper & .966 & .982 & .311 & .247 & .342 & .640 & .345 & .395 & .870 & .783 & .574 & .524 \\
\hline \multirow[t]{4}{*}{ 5. OANB_action } & $r$ & & $.920^{\mathrm{b}}$ & -.101 & .053 & .095 & .360 & .008 & .096 & $.772^{\mathrm{b}}$ & $.684^{\mathrm{b}}$ & .260 & .042 \\
\hline & $N$ & & 29 & 29 & 30 & 30 & 30 & 30 & 30 & 30 & 30 & 30 & 30 \\
\hline & 95\% C. I. Lower & & .690 & -.449 & -.525 & -.469 & -.209 & -.468 & -.087 & .340 & .348 & -.177 & -.295 \\
\hline & Upper & & .985 & .156 & .207 & .323 & .657 & .200 & .395 & .887 & .837 & .517 & .324 \\
\hline \multirow[t]{4}{*}{ 9. OANB_object } & $r$ & & & .027 & .060 & .142 & $.438^{\mathrm{a}}$ & -.008 & .169 & $.643^{\mathrm{b}}$ & $.548^{\mathrm{b}}$ & .277 & .017 \\
\hline & $N$ & & & 28 & 29 & 29 & 29 & 29 & 29 & 29 & 29 & 29 & 29 \\
\hline & 95\% C. I. Lower & & & -.195 & -.512 & -.358 & -.141 & -.439 & .035 & .224 & .319 & -.068 & -.372 \\
\hline & Upper & & & .236 & .261 & .360 & .679 & .161 & .438 & .861 & .801 & .501 & .268 \\
\hline \multirow[t]{4}{*}{ 13. Lesion Size } & $r$ & & & & -.026 & .031 & .113 & -.193 & .146 & -.182 & -.197 & -.293 & -.310 \\
\hline & $N$ & & & & 32 & 32 & 32 & 32 & 32 & 32 & 32 & 32 & 32 \\
\hline & 95\% C. I. Lower & & & & -.321 & -.228 & -.177 & -.468 & -.282 & -.558 & -.565 & -.487 & -.698 \\
\hline & Upper & & & & .328 & .393 & .451 & .102 & .564 & .192 & .267 & .079 & .044 \\
\hline \multirow[t]{4}{*}{ 17. Total Utterance } & $r$ & & & & & $.912^{\mathrm{b}}$ & $.695^{\mathrm{b}}$ & $.875^{\mathrm{b}}$ & $.352^{\mathrm{a}}$ & .153 & -.002 & $.640^{\mathrm{b}}$ & .233 \\
\hline & $N$ & & & & & 49 & 49 & 49 & 49 & 49 & 49 & 49 & 49 \\
\hline & 95\% C. I. Lower & & & & & .698 & .160 & .533 & -.324 & -.248 & -.467 & .130 & -.097 \\
\hline & Upper & & & & & .936 & .729 & .930 & .499 & .353 & .042 & .688 & .624 \\
\hline \multirow[t]{4}{*}{ 21. Words } & $r$ & & & & & & $.825^{\mathrm{b}}$ & $.914^{\mathrm{b}}$ & $.601^{\mathrm{b}}$ & .230 & .101 & $.721^{\mathrm{b}}$ & .262 \\
\hline & $N$ & & & & & & 49 & 49 & 49 & 49 & 49 & 49 & 49 \\
\hline & 95\% C. I. Lower & & & & & & .521 & .535 & .311 & -.055 & -.313 & .290 & -.111 \\
\hline & Upper & & & & & & .849 & .965 & .801 & .549 & .341 & .810 & .575 \\
\hline \multirow[t]{4}{*}{ 25. Nouns } & $r$ & & & & & & & $.651^{\mathrm{b}}$ & $.547^{\mathrm{b}}$ & $.340^{\mathrm{a}}$ & .183 & $.437^{\mathrm{b}}$ & .011 \\
\hline & $N$ & & & & & & & 49 & 49 & 49 & 49 & 49 & 49 \\
\hline & 95\% C. I. Lower & & & & & & & .166 & .110 & .160 & .186 & .191 & .185 \\
\hline & Upper & & & & & & & .062 & .373 & .089 & -.210 & -.103 & -.394 \\
\hline \multirow[t]{4}{*}{ 29. Verbs } & $r$ & & & & & & & & $.551^{\mathrm{b}}$ & .172 & .046 & $.786^{\mathrm{b}}$ & $.353^{\mathrm{a}}$ \\
\hline & $N$ & & & & & & & & 49 & 49 & 49 & 49 & 49 \\
\hline & 95\% C. I. Lower & & & & & & & & -.013 & -.316 & -.488 & .476 & .028 \\
\hline & Upper & & & & & & & & .683 & .407 & .129 & .845 & .714 \\
\hline \multirow[t]{4}{*}{ 33. MLU } & $r$ & & & & & & & & & $.283^{\mathrm{a}}$ & .252 & $.459^{\mathrm{b}}$ & .253 \\
\hline & $N$ & & & & & & & & & 49 & 49 & 49 & 49 \\
\hline & 95\% C. I. Lower & & & & & & & & & .133 & .049 & .092 & -.351 \\
\hline & Upper & & & & & & & & & .645 & .604 & .664 & .424 \\
\hline \multirow[t]{4}{*}{ 37. Narrative Complexity } & $r$ & & & & & & & & & & $.927^{\mathrm{b}}$ & $.435^{\mathrm{b}}$ & .211 \\
\hline & $N$ & & & & & & & & & & 49 & 49 & 49 \\
\hline & 95\% C. I. Lower & & & & & & & & & & .797 & .253 & -.217 \\
\hline & Upper & & & & & & & & & & .955 & .681 & .577 \\
\hline \multirow[t]{4}{*}{ 41. Search Theme } & $r$ & & & & & & & & & & & $.369^{\mathrm{b}}$ & .221 \\
\hline & $N$ & & & & & & & & & & & 49 & 49 \\
\hline & 95\% C. I. Lower & & & & & & & & & & & .074 & -.288 \\
\hline & Upper & & & & & & & & & & & .596 & .602 \\
\hline \multirow[t]{4}{*}{ 45. Evaluation } & $r$ & & & & & & & & & & & & $.530^{\mathrm{b}}$ \\
\hline & $N$ & & & & & & & & & & & & 49 \\
\hline & 95\% C. I. Lower & & & & & & & & & & & & .283 \\
\hline & Upper & & & & & & & & & & & & .754 \\
\hline \multirow[t]{4}{*}{ 49. Evaluative Diversity } & $r$ & & & & & & & & & & & & 1 \\
\hline & $N$ & & & & & & & & & & & & 49 \\
\hline & 95\% C. I. Lower & & & & & & & & & & & & 1 \\
\hline & Upper & & & & & & & & & & & & 1 \\
\hline
\end{tabular}

and $95 \%$ confidence intervals were derived from 1000 bootstrap samples.

a Correlation is significant at the .05 level (2-tailed).

${ }^{\mathrm{b}}$ Correlation is significant at the .01 level (2-tailed).

Action Naming Battery's action $(r=.772, p<.001)$ and object scores $(r$ $=.643, p<.001)$. Significant positive correlations were also found between the narrative complexity scores and the production of nouns ( $r$ $=.34, p=.017$ ), and MLU scores $(r=.283, p=.049)$ (see Table 2 ).

In sum, the results indicated poorer performance for the people with LHD as a group in narrative complexity compared to the controls. When education level was controlled, this difference was not significant. However, people with LHD were deficient in maintaining the stories' overall theme. Single case analyses revealed more granular findings.
Lesions in the frontotemporal regions of the right hemisphere and frontal regions in the left hemisphere were linked to decreased complexity in narration.

\subsection{The evaluation of the story}

A univariate ANOVA indicated no difference among groups for evaluative diversity, $F(2,46)=1.684, p=.197, \eta^{2}=.07$ (for CIs see Table 6). Since the groups' stories did not differ significantly in length 
Table 3

Single case statistics profile of people with LHD and RHD for narrative complexity.

\begin{tabular}{|c|c|c|c|c|c|c|c|c|c|}
\hline \multicolumn{3}{|c|}{ Control Sample } & \multicolumn{7}{|l|}{ Patients } \\
\hline & & & & & & & Significance Test & Estimated & tion obtaining lower score than case \\
\hline $\mathrm{n}$ & Mean & SD & Lesion Side & ID & Scores & $\mathrm{t}$ & $p$ & Point (\%) & 95\% CI lower limit (\%) \\
\hline \multirow[t]{11}{*}{13} & 16.31 & 1.25 & Left & TD_360 & 3 & -10.261 & .000 & .00 & .00 \\
\hline & & & & MC_577 & 5 & -8.719 & .000 & .00 & .00 \\
\hline & & & & UD_618 & 6 & -7.948 & .000 & .00 & .00 \\
\hline & & & & CC_749 & 6 & -7.948 & .000 & .00 & .00 \\
\hline & & & & IG_363 & 9 & -5.635 & .000 & .01 & .00 \\
\hline & & & & KM_642 & 12 & -3.323 & .006 & .30 & .00 \\
\hline & & & & KD_493 & 12 & -3.323 & .006 & .30 & .00 \\
\hline & & & Right & HX_252 & 2 & -11.032 & .000 & .00 & .00 \\
\hline & & & & KG_593 & 7 & -7.177 & .000 & .00 & .00 \\
\hline & & & & RT_309 & 10 & -4.864 & .000 & .02 & .00 \\
\hline & & & & DX_444 & 11 & -4.093 & .001 & .07 & .00 \\
\hline
\end{tabular}

Table 4

Production of evaluative devices ( 1 , Control, $\mathrm{n}=13 ; 2$, LHD, $\mathrm{n}=18$; 3 , RHD, $\mathrm{n}=18$ ).

\begin{tabular}{lllll}
\hline & Group & Mean & SD & Range \\
\hline Cognitive inferences & 1 & 11.62 & 5.58 & $3-24$ \\
& 2 & 8.33 & 6.43 & $0-27$ \\
Social engagement & 3 & 11.28 & 5.83 & $1-20$ \\
& 1 & 3.54 & 4.61 & $0-13$ \\
Affective states and behaviors & 2 & 1.33 & 1.78 & $0-7$ \\
& 3 & 2.39 & 3.07 & $0-9$ \\
Enrichment expressions & 1 & 4.7 & 3.17 & $2-14$ \\
& 2 & 2.89 & 2.54 & $0-10$ \\
Hedges & 3 & 3.67 & 2.87 & $0-12$ \\
& 1 & 6.38 & 2.72 & $3-13$ \\
& 2 & 4 & 2.5 & $0-10$ \\
Evaluative remarks & 3 & 7.39 & 5.5 & $1-18$ \\
& 1 & 10.92 & 7.98 & $3-27$ \\
& 2 & 4.94 & 3.92 & $0-12$ \\
& 3 & 7.11 & 6.25 & $0-23$ \\
& 1 & .69 & 1.03 & $0-3$ \\
& 2 & .28 & .46 & $0-1$ \\
& 3 & .94 & 1.98 & $0-8$ \\
\hline
\end{tabular}

as measured by the total number of utterance, the evaluation scores were analyzed as total raw scores rather than dividing the total number of evaluative devices by the total number of utterances for each subject. Yet, a significant main effect of group on the production of evaluative devices was revealed, $F(2,46)=4.412, p=.018, \eta^{2}=.16$ (see Fig. 4). The people with LHD produced fewer evaluative devices $(M=21.78$, $S D=13.84)$ than controls $(M=37.85, S D=13$. 78), (Bonferroni, $p=.021$ ).

Further analyses on subcategories of evaluative devices revealed no significant difference among groups for cognitive inferences, $F(2,46)$
$=1.521, p=.229, \eta^{2}=.06$, social engagement devices, $F(2,46)=1.808$, $p=.176, \eta^{2}=.07$, references to affective states and behaviors, $F(2,46)$ $=1.524, p=.229, \eta^{2}=.06$, and evaluative remarks, $F(2,46)=1.121$, $p=.335, \eta^{2}=.05$ (for CIs see Table 6). However, the use of enrichment devices differed among groups, $F(2,46)=3.499, p=.039, \eta^{2}=.13$. The people with LHD produced fewer enrichment devices $(M=4, S D$ $=2.50)$ than the people with RHD $(M=7.39, S D=5.50)$, (Bonferroni, $p=.039$ ). The use of hedges also differed among groups, $p=.033$, $\eta^{2}=.14$. The people with LHD produced fewer hedges $(M=4.94, S D$ $=3.92)$ than the controls $(M=10.92, S D=7.98)$, (Bonferroni, $p=.028$ ) (see Table 4).

Application of the Bayesian test revealed only 2 people with LHD who were impaired in including story components in their narratives, $p<.05$ (see Table 5).

The use of evaluative devices correlated positively with WAB scores $(r=.386, p=.032)$, the production of total utterance $(r=.64$, $p<.001)$, word $(r=.721, p<.001)$, noun $(r=.437, p=.002)$, verb ( $r=.786, p<.001)$, and the MLU scores $(r=.459, p=.001)$. A significant correlation was also found between the use of evaluative devices and the narrative complexity $(r=.435, p=.002)$. The evaluative diversity scores were positively correlated with verb production $(r$ $=.353, p=.013$ ) (see Table 2).

\section{Discussion}

The purpose of the study was to investigate the neural underpinnings of macrolinguistic level language production by focusing on complexity and the use of evaluative devices in narration. First, we found that LHD people's narratives were less complex as indicated by fewer story components included in their narratives compared to control participants, but this effect was influenced by LHD people's education level. However, lesions to the left middle, inferior and superior frontal gyrus, and left insula were linked to poorer perfor-

Table 5

Single case statistics profile of people with LHD and RHD for evaluative devices.

\begin{tabular}{|c|c|c|c|c|c|c|c|c|c|}
\hline \multicolumn{3}{|c|}{ Control Sample } & \multicolumn{7}{|l|}{ Patients } \\
\hline & & & & & & & Significance Test & Estimated & tion obtaining lower score than case \\
\hline $\mathrm{n}$ & Mean & SD & Lesion Side & ID & Scores & $\mathrm{t}$ & $p$ & Point (\%) & 95\% CI lower limit (\%) \\
\hline \multirow[t]{2}{*}{13} & 37.85 & 13.78 & Left & TD_360 & 6 & -2.227 & .046 & 2.29 & .04 \\
\hline & & & & IG_363 & 0 & -2.647 & .021 & 1.07 & .00 \\
\hline
\end{tabular}


Confidence intervals for all $\mathrm{F}$ statistics presented, 95\% confidence intervals were derived from 1000 bootstrap samples.

\begin{tabular}{|c|c|c|c|c|c|c|}
\hline & \multicolumn{2}{|l|}{ Control-left } & \multicolumn{2}{|l|}{ Control-right } & \multicolumn{2}{|l|}{ Left-right } \\
\hline & Lower-bound & Upper-bound & Lower-bound & Upper-bound & Lower-bound & Upper-bound \\
\hline WAB & & & & & -11.226 & -2.033 \\
\hline OANB_action & & & & & -11.926 & 1.903 \\
\hline OANB_object & & & & & -17.251 & -.053 \\
\hline Total utterance & -4.011 & 12.327 & -8.149 & 9.754 & -11.136 & 4.499 \\
\hline Words & -5.712 & 166.699 & -78.132 & 107.624 & -143.912 & 21.392 \\
\hline Nouns & -2.423 & 27.208 & -23.813 & 13.017 & -35.995 & 2.227 \\
\hline Verbs & 1.414 & 31.320 & -7.962 & 21.200 & -22.321 & 2.388 \\
\hline MLU & .842 & 2.786 & .027 & 2.160 & -1.445 & -.020 \\
\hline Narrative complexity & 1.583 & 6.175 & .250 & 4.227 & -4.389 & 1.263 \\
\hline Plot onset & .233 & 2.105 & .048 & 1.930 & -1.434 & .965 \\
\hline Plot unfolding & .296 & 1.590 & -.212 & .953 & -1.400 & .136 \\
\hline Plot resolution & .118 & .579 & .053 & .438 & -.407 & .186 \\
\hline Search theme & .626 & 2.250 & .062 & 1.472 & -1.768 & .265 \\
\hline Establishing search theme & .084 & 1.008 & -.036 & .678 & -.786 & .310 \\
\hline Maintaining search theme & .373 & 1.307 & .012 & .818 & -.973 & .119 \\
\hline Evaluation & 6.385 & 25.557 & -6.153 & 15.491 & -21.398 & -1.051 \\
\hline Evaluative diversity & -.071 & 1.605 & -.125 & 1.030 & -1.035 & .428 \\
\hline Cognitive inferences & -1.605 & 7.436 & -3.665 & 4.181 & -6.819 & 1.234 \\
\hline Social engagement & -.277 & 5.346 & -1.644 & 4.286 & -2.759 & .573 \\
\hline Affective states and behaviors & -.104 & 4.221 & -.919 & 3.461 & -2.619 & .948 \\
\hline Enrichment expressions & .611 & 4.414 & -4.130 & 2.006 & -6.271 & -.701 \\
\hline Hedges & 1.462 & 10.651 & -1.041 & 9.116 & -5.644 & .999 \\
\hline Evaluative remarks & -.161 & 1.035 & -1.354 & .699 & -1.733 & .136 \\
\hline
\end{tabular}

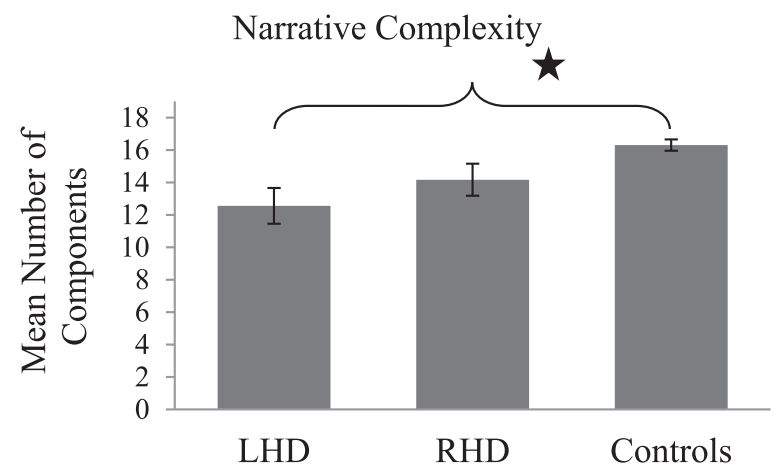

Fig. 2. Mean number of story components included in the narratives of people with LHD and RHD, and controls. * $p<.05$.

mance in narrative complexity. As establishing and maintaining the story's search theme is a good index of story coherence (Ash et al., 2006; Reilly et al., 1998), we also compared the groups' initial and subsequent mention of the search theme. Even though people with LHD could establish the story's search theme, they did not sustain this theme throughout the story. As a group people with RHD performed similarly to controls, however, analyses of individual cases indicated that people with frontotemporal lesions produced poorer narratives compared to controls. Second, the evaluative aspect of LHD people's narratives was also found to be impaired compared to controls. When we examined specific evaluative devices, LHD people's narratives included less hedges (i.e., devices that indicate a level of certainty/uncertainty) compared to controls and less enrichment expressions compared to people with RHD. Our results revealed preserved performance for people with RHD in the evaluative aspect of narratives.

\subsection{Narrative complexity}

Complexity in narrative is an indicator of a speaker's use of proper and rich language and is important for communicative competence. Although telling a story from sequenced pictures may seem simple, it involves many steps such as recognizing the setting, characters, actions, and the outcome while maintaining the overall theme of the story and realizing when a resolution is reached (Ash et al., 2006). People with LHD mention fewer components of a story and have problems maintaining a storyline (even though they do not have a problem in initiating the story theme), and understanding the motivation for the protagonists' continuing actions, and the overall theme of the story. These results indicate that as a group, people with LHD had difficulty producing coherent and complex narratives that contain basic informational components of the story while keeping in mind the story's overall theme. It is important to emphasize that even though our results did not indicate poorer performance for people with RHD than controls in these aspects of narratives, the results did not differentiate RHD people's performance from those of people with LHD either.

Results regarding the reduction in narrative complexity in people with LHD are consistent with previous findings suggesting macrolinguistic level impairments in narrative production for these people (e.g., Bloom et al., 1992; Coelho et al., 2002; Ulatowska et al., 1981, 1983). In particular, lesions to the middle, inferior and superior frontal gyrus, and left insula were linked to poorer performance in narrative complexity as indicated by the analysis of individual cases. The ability to produce and meaningfully organize connected language can be partly predicted by overall linguistic functioning assessed by the standardized tests. Indeed, we found that LHD and RHD people's narrative complexity scores were related to their aphasia, object, and action naming scores (see also Bloom et al., 1992; Ulatowska et al., 1983). Thus, the quality of the narrative impaired in people with LHD may be an outcome of microlinguistic deficits.

Our results about people with RHD are surprising. The current literature would not predict preserved performance for people with RHD in content and coherence (e.g., Bloom et al., 1996). One difference in our study compared to others could be differences in stimuli used to elicit narrative production. For instance, Uryase, Duffy and Liles (1991) examined narratives of people with aphasia and people with RHD and healthy controls elicited by a video rather than pictures. Both people with aphasia and people with RHD produced less informative narratives compared to controls. The differences in the visual complexity of videos may play a role in RHD people's narrative performance since the right hemisphere is associated with visual information processing (Meadows, 1974). In addition, even though we did not find any group differences between people with RHD and controls, we found individual cases who 


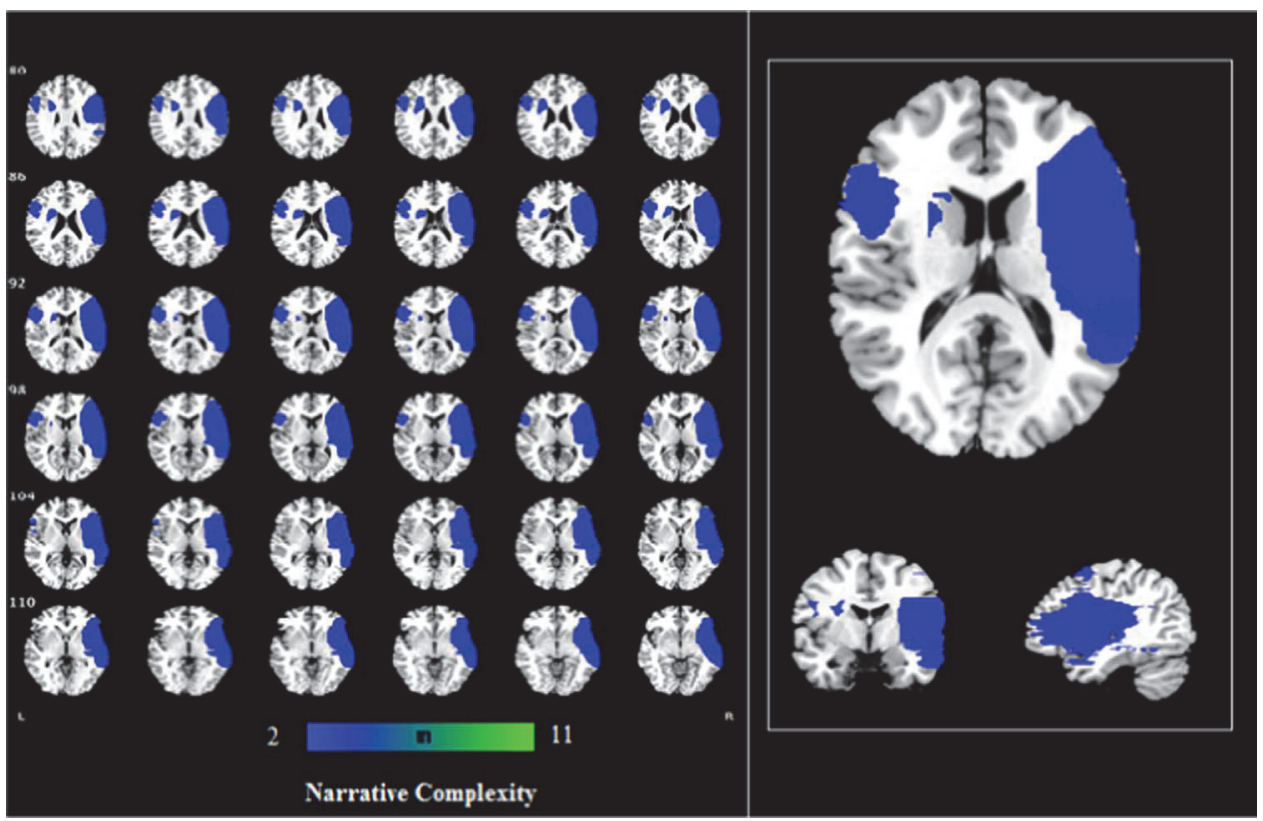

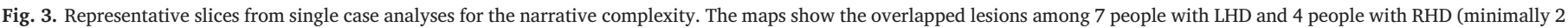
participants have lesions on a specific area).

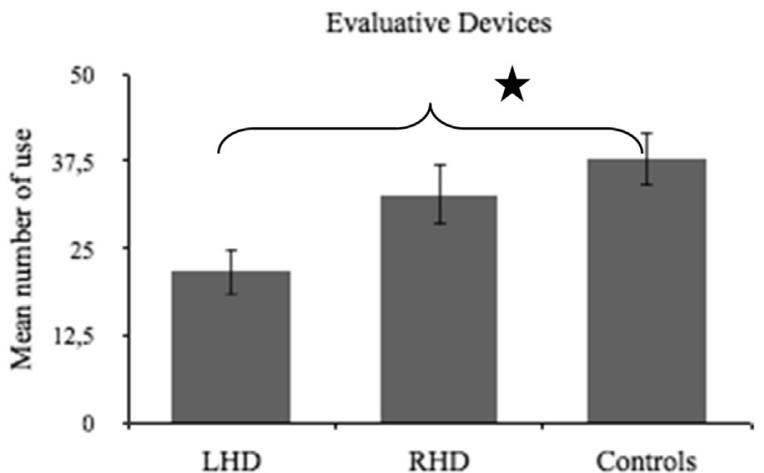

Fig. 4. Mean number of evaluative devices used in the narratives of the people with LHD and RHD, and controls. * $p<.05$.

were impaired at producing a complex narrative (i.e. people with RHD scoring significantly below the scores of controls). Lesions to the right frontal lobe including the dorsolateral prefrontal cortex, both the anterior and superior temporal gyrus, the middle temporal gyrus, and the supramarginal gyrus were linked to poor performance in narrative complexity.

Consistent with our findings, several fMRI studies investigating processing of narrative coherence showed greater activation in bilateral medial and lateral frontal and anterior temporal and left medial prefrontal regions (Ferstl et al., 2002; Fletcher et al., 1995; Gallagher et al., 2000; Mazoyer et al., 1993; Xu, Kemeny, Park, Frattali, and Braun, 2005, Troiani et al., 2008). Coelho and colleagues (2012) also reported that individuals with left DLPFC lesions have deficits in inclusion of critical story components and in global coherence. Recent tDCS studies also demonstrate that stimulation over the left inferior frontal gyrus improves the cohesion (Marangolo et al., 2014) and informativeness of speech samples (Marangolo et al., 2013). Additionally, Transcranial Magnetic Stimulation (rTMS) stimulation over the dorsal portion of the left anterior inferior frontal gyrus, but not right, diminishes global coherence and lexical informativeness of narratives (Marini and Urgesi, 2012). In a review of fMRI studies on the anatomy of language, Price (2010) identifies several regions in the left hemisphere involved in word retrieval processes that were damaged in our people with LHD, who performed worse than controls in narrative complexity: the inferior and middle frontal area, and both dorsal and ventral pars opercularis. In our data, the narrative complexity scores were related to both object and action naming scores and total number of nouns used. Thus, we might suggest that people with LHD with lesions to these regions in the frontal area have problems producing complex narratives because of their word finding difficulties.

A relationship between lexical access difficulty and production of reduced narrative content was also observed in another study of patients with frontotemporal dementia (Ash et al., 2006). In this study, semantic dementia patients' narratives had reduced content with a high rate of incomplete and missing elements compared to controls. These findings together with our results suggest that the production of an informative narrative through inclusion of important content elements of the story can depend on the ability to access necessary lexical items to express these contents.

The lesions of people with RHD that we found to be related to reduced narrative complexity are also similar to cortical atrophy profile of frontotemporal dementia patients with social and executive deficits. These patients have damage in their prefrontal, ventral frontal, and anterior temporal brain regions, often more prominently on the right than the left (Grossman et al., 2004; Rosen et al., 2002; Williams et al. 2005). Limited connectedness in those patients' narratives reflects problems in organizing and relating the events in narratives and maintaining the overall theme (Ash et al., 2006). These impaired abilities can be linked to executive resources such as organization, planning and working memory, which are required to relate the events in the narrative, to infer cause and effect relationship, and to understand the main point or goal of a story (Mar, 2004). Gernsbacher and Kaschak (2003) also identified the right temporal and frontal regions as important areas for the integrative aspects of narrative processing, emphasizing the hypothesis that the activation observed in these areas specific to discourse processing might be a function of memory processes that maintain the coherence of the narrative across sentences. Yet, there is no consensus on the specific cognitive processes involved in global coherence (Kurczek and Duff, 2011; Mar, 2004; Marini et al., 2011b; Rogalski and Edmunds, 2008).

In sum, we found that as a group people with LHD had problems in keeping the overall theme in mind. As a group, people with RHD could tell a coherent story and maintaining the overall theme. Nevertheless, we found that lesions to the frontotemporal regions including almost 
the entire frontal cortex, both the anterior and superior temporal gyrus and the middle temporal gyrus, and supramarginal gyrus were linked to poor performance in narrative complexity. For the left hemisphere, lesions to the frontal cortex including the middle, inferior and superior frontal gyrus, and left insula were related to narrative complexity.

\subsection{The evaluative aspect of narratives}

The use of evaluative references is an important element of a good narrative that makes events and actions in the story more meaningful and maintains listeners' attention and involvement (Bamberg and Damrad-Frye, 1991; Labov and Waletzky, 1967; Reilly et al., 2004). Even though people with LHD included diverse types of evaluative devices in their stories, they used fewer evaluative devices compared to controls. While an intact left hemisphere seems to be necessary to produce rich stories in terms of evaluation, our data do not suggest the same for the right hemisphere. We found preserved performance for people with RHD in both diversity and frequency of evaluation.

These findings are consistent with the previous research suggesting impaired performance in using evaluations for people with LHD (Ulatowska et al., 1981, 1983). Patients with aphasia produced fewer evaluations compared to controls both in terms of the number of clauses containing evaluation and the number of evaluative expressions per clause. The propositional analyses also revealed that patients with aphasia often omit propositions that contain inner feelings and motivations of the protagonists in the stories rather than their actions.

The reduction in evaluation might be a reflection of simplification of language since evaluative expressions involve complex syntactic devices. Evaluation also has a secondary role in narrative structure and communicates relatively less important information within a narrative compared to other essential elements of the story such as setting and resolution (Ulatowska et al., 1981). Therefore, the reason for using less evaluative expressions might be related to either their function or form (more complex syntax), or combination of both. In our study, the use of evaluation also correlated with LHD and RHD people's aphasia scores, suggesting that producing a rich narrative may depend on overall linguistic skills. Indeed, we identified two people with LHD who scored significantly lower for the use of evaluation relative to controls. These participants were quite effortful in their speech, keeping them away from enriching their narratives with the use of evaluative devices.

We expected a specific impairment for people with RHD in mentioning affective states and behaviors of the protagonists in the story based on the role of right hemisphere in detecting emotional nuances and understanding the emotional importance of pictured scenes (e.g., Bloom et al., 1992; Cicone, Wapner, and Gardner, 1980; DeKosky, Heilman, Bowers, and Valenstein, 1980; Moscovitch, 1983), and in lexical emotional expression (Borod et al., 2002). These inconsistencies may result from the differences in measures of emotional expression (Cimino et al., 1991; Heberlein et al., 2003). For instance, Cimino and colleagues (1991) investigated the emotional verbal expression using recalled autobiographical memories, in which participants were asked to produce narratives as a response to a cue word such as "angry" or "surprised". The RHD people's reports were rated less on emotionality compared to controls. People with RHD also used fewer appraisals (e.g., affect, judgment) compared to controls in expressing emotions in their personal narratives. This could be due to impairment in talking about authorial (first person) affect as opposed to non-authorial (second or third person) one such as providing information about feelings of others in a retelling or a sequenced picture task (Sherratt, 2007). In our study, participants were required to report on the actions and the feelings/motivations of the protagonists in a pictured story, and we indicated comparable evaluative performance for people with RHD and controls when they provide non-authorial affect.

Future research could focus on a specific point in the narrative structure (e.g., setting), where the evaluative devices are used rather than examining only frequency or diversity of evaluation. Evaluative devices mark and put emphasis on a particular part of a discourse (Cortazzi and Jin, 2000) by usually being used before the peak of the narrative (Labov, 1997). Besides using relatively fewer evaluative devices in their narratives, people with LHD may also use evaluation at unusual points. Likewise, even though people with RHD have comparable frequency of evaluation use to control participants, they might be impaired at using evaluative devices in the proper points in the narrative. Thus, an investigation of the detail points of evaluative devices can be helpful in understanding the nature of macrolevel language problems of focal brain-injured people. The narrative coherence and evaluative devices could also be examined in a larger control group.

Taken together, our results showed that people with LHD, particularly having frontal lesions, were deficient in both macrolinguistic measures, narrative complexity and evaluations, assessed in this paper. These macrolevel deficits correlated with their microlinguistic deficits. We showed that lesions to certain areas of frontotemporal regions of the right hemisphere and frontal regions and insula of the left hemisphere contribute to narrating a complex story. This study adds to the limited amount of literature on the use of evaluation in unilateral brain damaged people and to the literature showing conflicting findings on narrative measures such as informativeness and coherence. We also expand our knowledge on the cortical regions that are essential for the production of complex narratives. These findings suggest that LHD people's poor production can be related to their overall language problems whereas RHD people's impaired abilities can be associated with other cognitive impairments such as planning and working memory.

\section{Acknowledgements}

This research was supported in part by NIH RO1DC012511 and grants to the Spatial Intelligence and Learning Center, funded by the National Science Foundation (subcontracts under SBE- 0541957 and SBE-1041707). We would like to thank everyone in the Chatterjee Lab for their helpful comments in this research with special thanks to Marianna Stark and Eileen Cardillo for their help in recruiting people with brain injury. We also thank Aylin Küntay, Hande Ilgaz, and Ece Demir for their valuable feedback on the previous versions of the manuscript, Language and Cognition Lab members at Koç University for discussions about the project, and Hilal Demircan for helping with reliability coding.

APPENDIX A. : Definition and examples of coding for narrative complexity (adapted from Berman and Slobin, 1994; Köksal, 2011)

\begin{tabular}{lll}
\hline $\begin{array}{l}\text { Plot } \\
\text { components }\end{array}$ & Plot Sub-Components & Examples and Explanations \\
\hline \multirow{2}{*}{ Plot onset } & $\begin{array}{l}\text { Precedent event } \\
\text { Temporal location }\end{array}$ & $\begin{array}{l}\text {-The boy and the dog wakes up } \\
\text {-In the morning/evening }\end{array}$ \\
& Characters & $\begin{array}{l}\text { The boy/child/kid, the dog, the frog } \\
\text { Scoring ranges between 0-3: }\end{array}$
\end{tabular}




\begin{tabular}{|c|c|c|}
\hline & & $\begin{array}{l}\text { Only one character }=1 \\
\text { Two of the characters }=2 \\
\text { Three characters }=3\end{array}$ \\
\hline & $\begin{array}{l}\text { The main characters learn } \\
\text { something }\end{array}$ & $\begin{array}{l}\text {-The boy and the dog noticed that the frog had gone missing-The boy and the dog wake up and see } \\
\text { that the frog is gone }\end{array}$ \\
\hline & $\begin{array}{l}\text { Inference about the frog's } \\
\text { disappearance }\end{array}$ & -The frog escaped from the jar-The frog is gone-The jar is empty \\
\hline & The response of protagonist & -They are fascinated by the frog's disappearance-The boy was shocked \\
\hline & Encountering the bees & -The dog is looking into the beehive-The bees are chasing the dog \\
\hline & Encountering the gopher & -The boy is looking down a hole and a gopher comes out-The boy gets bitten by a gopher \\
\hline & Encountering the owl & -The boy falls down because an owl comes out of the tree-The boy disturbed an owl in the tree \\
\hline & Encountering the deer & -The child climbs on the deer-The deer tosses the boy over the cliff \\
\hline & Falling down & -The boy and the dog falls in the water/pond/lake \\
\hline Resolution & $\begin{array}{l}\text { Protagonist finds the lost } \\
\text { frog }\end{array}$ & -The kid finds his frog \\
\hline & Reiteration of search theme & $\begin{array}{l}\text {-Whether the search theme was reiterated later. } \\
\text { (range: } 0-2 \text { ). }\end{array}$ \\
\hline & & No additional mention $=0$ \\
\hline & & 1 or 2 additional mentions $=1$ \\
\hline & & Multiple additional mentions $=2$. \\
\hline
\end{tabular}

\section{APPENDIX B. Definition and examples of evaluation coding}

1. Cognitive inferences: inferences of character motivation, causality, and mental states, as in "Little boy climbs up a tree to see if the frog jumped in there" or "He's wondering what happened to the frog." Common examples included 'think', 'look for', 'because', 'investigate' etc.

2. Social engagement devices: using phrases or exclamations to capture addressee attention, e.g. sound effects, character speech accompanied by animated speech or intonation, and audience hookers, as in "Voila! He finds the frog!" or "The boy is over by the log saying "shh" to the dog". Statements of indirect speech were not included in the category.

3. References to affective states or behaviors, as in "Everyone seems to be happy" or "The boy was crying".

4. Enrichment expressions: adverbial phrases such as 'again' or 'quickly' that reveal the unexpected or inferred nature of an action; intensifiers such as 'very' or 'so'; and repetitions which draw the audience's attention to a certain event as in "He's running running running"; connectives such as 'but', 'however' or 'instead' that informs about the unexpected or contrastive occurrences of events.

5. Hedges: distancing devices that indicate a level of certainty/uncertainty, suggesting the narrator's non-commitment to the truth value of the proposition. Common examples included 'seems like', 'looks like', 'kind of', 'probably', 'I guess/think', etc.

6. Evaluative remarks: the narrators' reflections about the events of the narrative which communicate a subjective point of view as in "This was something stupid to do" or "The dog is not hurt, that's a good thing"

\section{References}

Andreetta, S., Cantagallo, A., Marini, A., 2012. Narrative discourse in anomic aphasia. Neuropsychologia 50, 1787-1793.

Armstrong, E., Ulatowska, H., 2007. Making stories: evaluative language and the aphasia experience. Aphasiology 21 (6-8), 763-774.

Ash, S., Moore, P., Antani, S., McCawley, G., Work, M., Grossman, M., 2006. Trying totell a tale: discourse impairments in progressive aphasia and frontotemporaldementia. Neurology 66 (9), 1405-1413.

Bamberg, M., Damrad-Frye, R., 1991. On the ability to provide evaluative comments:Further explorations of children's narrative competencies. J. Child Lang. 18 (03), 689-710.

Bartels-Tobin, L.R., Hinckley, J.J., 2005. Cognition and discourse production in righthemisphere disorder. J. Neurolinguist. 18 (6), 461-477.

Berko- Gleason, J.B., Goodglass, H., Obler, L., Green, E., Hyde, M.R., Weintraub, S., 1980. Narrative strategies of aphasic and normal-speaking subjects. J. Speech, Lang., Hear. Res. 23 (2), 370-382.

Berman, R.A., Slobin, D.I., 1994. Relating Events In Narrative: A Cross Linguistic Developmental Study. 41-42. NJ: Erlbaum, Hillsdale, pp. 20-21.

Bloom, R.L., Borod, J.C., Obler, L.K., Gerstman, L.J., 1992. Impact of emotional content on discourse production in patients with unilateral brain damage. Brain Lang. 42 (2), 153-164.

Bloom, R.L., Borod, J.C., Santschi-Haywood, C., Pick, L.H., Obler, L.K., 1996. Leftand right hemispheric contributions to discourse coherence and cohesion. Int. J. Neurosci. 88 (1-2), 125-140.

Borod, J.C., Bloom, R.L., Brickman, A.M., Nakhutina, L., Curko, E.A., 2002. Emotional processing deficits in individuals with unilateral brain damage. Appl. Neuropsychol. 9, 23-36.

Braun, A.R., Guillemin, A., Hosey, L., Varga, M., 2001. The neural organization of discourse. Brain 124, 2028-2044.

Christiansen, J.A., 1995. Coherence violations and propositional usage in the narratives of fluent aphasics. Brain Lang. 51, 291-317.

Cicone, M., Wapner, W., Gardner, H., 1980. Sensitivity to emotional expressions and situations in organic patients. Cortex 16 (1), 145-158.

Cimino, C.R., Verfaellie, M., Bowers, D., Heilman, K.M., 1991. Autobiographical memory: influence of right hemisphere damage on emotionality and specificity. Brainand Cogn. 15 (1), 106-118.

Coelho, C., Lê, K., Mozeiko, J., Krueger, F., Grafman, J., 2012. Discourse productionfollowing injury to the dorsolateral prefrontal cortex. Neuropsychologia 50, 3564-3572.

Cortazzi, M., Jin, L., 2000. Evaluating evaluation in narrative. In: Hunston, S., Thompson, G. (Eds.), Evaluation in text: Authorial stance and the construction of discourse. Oxford University Press, Oxford, UK.

Crawford, J.R., Garthwaite, P.H., Porter, S., 2010. Point and interval estimates of effectsizes for the case-controls design in neuropsychology: rationale, methods, implementations, and proposed reporting standards. Cognitive Neuropsychol. 27, 245-260.

Davis, G.A., O'Neil-Pirozzi, T.M., Coon, M., 1997. Referential cohesion and logical coherence of narration after right hemisphere stroke. Brain Lang. 56, 183-210.

DeKosky, S.T., Heilman, K.M., Bowers, D., Valenstein, E., 1980. Recognition and discrimination of emotional faces and pictures. Brain Lang. 9 (2), 206-214.

Delis, D.C., Wapner, W., Gardner, H., Moses, J.A., 1983. The contribution of the righthemisphere to the organization of paragraphs. Cortex 19, 43-50. 
Dressler, W.U., Pleh, C., 1988. On text disturbances in aphasia. In: Linguistic Analyses of Aphasic Language. Springer, New York, pp. 151-178.

Druks, J., 2000. Object Action Namin. Battery.

Fellows, L.K., Stark, M., Berg, A., Chatterjee, A., 2008. Patient registries in cognitiveneuroscience research: Advantages, challenges, and practical advice. Journal Cogn. Neurosci. 20, 1107-1113.

Ferstl, E.C., von Cramon, D.Y., 2002. What does the frontomedian cortex contribute to language processing: coherence or theory of mind? Neuroimage 17, 1599-1612.

Ferstl, E.C., Neumann, J., Bogler, C., Von Cramon, D.Y., 2008. The extended language network: a meta-analysis of neuroimaging studies on text comprehension. Hum. Brain Mapp. 29, 581-593.

Fletcher, P.C., Happe, F., Frith, U., Baker, S.C., Dolan, R.J., Frackowiak, R.S., Frith, C.D., 1995. Other minds in the brain: a functional imaging study of "theory of mind" in story comprehension. Cognition 57, 109-128.

Freedman-Stern, R., Ulatowska, H.K., Baker, T., DeLacoste, C., 1984. Disruption of written language in aphasia: a case study. Brain Lang. 22, 181-205.

Gallagher, H.L., Happé, F., Brunswick, N., Fletcher, P.C., Frith, U., Frith, C.D., 2000. Reading the mind in cartoons and stories: an fMRI study of 'theory of mind' in verbal and nonverbal tasks. Neuropsychologia 38, 11-21.

Gernsbacher, M.A., Kaschak, M.P., 2003. Neuroimaging studies of language productionand comprehension. Annual Rev. Psychol. 54, 91.

Glosser, G., 1993. Discourse production patterns in neurologically impaired and agedpopulations. In: Brownell, H., Joanette, Y. (Eds.), Narrative discourse in neurogenically impaired and normally aging adults. CA: Singular, San Diego, pp. 191-212.

Glosser, G., Deser, T., 1990. Patterns of discourse production among neurological patients with fluent language disorders. Brain Lang. 40, 67-88.

Glosser, G., Deser, T., Weisstein, C., 1992. Structural organization of discourse production following right hemisphere damage. J. Clin. Exp. Neuropsychol. 14, 40.

Göksun, T., Lehet, M., Malykhina, K., Chatterjee, A., 2015. Spontaneous gesture and spatial language: evidence from focal brain-injury. Brain Lang. 150, 1-13.

Grossman, M., McMillan, C., Moore, P., Ding, L., Glosser, G., Work, M., Gee, J., 2004 What's in a name: voxel-based morphometric analyses of MRI and naming difficulty in Alzheimer's disease, frontotemporal dementia and corticobasal degeneration. Brain 127, 628-649.

Heberlein, A.S., Adolphs, R., Pennebaker, J.W., Tranel, D., 2003. Effects of Damage to Right-Hemisphere Brain Structures on Spontaneous Emotional and Social Judgments. Political Psychol. 24, 705-726.

Hécaen, H., Albert, M.L., 1978. Human Neuropsychology. Wiley, New York.

Herrmann, M., Koch, U., Johannsen-Horbach, H., Wallesch, C.W., 1989. Communicativeskills in chronic and severe nonfluent aphasia. Brain Lang. 37, 339-352.

Huber, W., Gleber, J., 1982. Linguistic and nonlinguistic processing of narratives in aphasia. Brain Lang. 16, 1-18.

Ianni, G.R., Cardillo, E.R., McQuire, M., Chatterjee, A., 2014. Flying under the radar: figurative language impairments in focal lesion patients. Front. Hum. Neurosci. 8.

Jakobson, R., 1980. On aphasic disorders from a linguistic angle. Framew. Lang. 93-111.

Joanette, Y., Goulet, P., Ska, B., Nespoulous, J.L., 1986. Informative content of narrative discourse in right-brain-damaged right-handers. Brain Lang. 29, 81-105.

Kertesz, A., 1982. Western aphasia battery test manual. Psychol. Corp.

Kintsch, W., 1994. Text comprehension, memory, and learning. Am. Psychol. 49, 294.

Köksal, 2011. Predictors of Turkish Speaking Preschoolers' Narrative And Vocabulary Competence: An Ecological Approach. (Unpublished Masters Thesis) Koç University, Istanbul-Turkey.

Küntay, A., Nakamura, K., 2004. Linguistic strategies serving evaluative functions: a comparison between Japanese and Turkish narratives. (Typological and contextualperspectives) In: Strömqvist, S., Verhoeven, L. (Eds.), Relating events in narrative 2. Lawrence Erlbaum Associates, Mahwah, pp. 329-358.

Kurczek, J., Duff, M.C., 2011. Cohesion, coherence, and declarative memory: discourse patterns in individuals with hippocampal amnesia. Aphasiology 25, 700-712.

Labov, W., 1997. Some further steps in narrative analysis. J. Narrat. Life Hist. 7, 395-415.

Labov, W., Waletzky, J., 1967. Narrative Analysis: Oral Versions of Personal Experience. University of Washington Press, Seattle.

Larfeuil, C., Dorze, G.L., 1997. An analysis of the word-finding difficulties and of the content of the content of the discourse of recent and chronic aphasic speakers. Aphasiology 11 (8), 783-811.

Linnik, A., Bastiaanse, R., Höhle, B., 2016. Discourse production in aphasia: a current review of theoretical and methodological challenges. Aphasiology 30, 765-800.

Mar, R.A., 2004. The neuropsychology of narrative: story comprehension, story productionand their interrelation. Neuropsychologia 42, 1414-1434.

Marangolo, P., Fiori, V., Calpagnano, M.A., Campana, S., Razzano, C., Caltagirone, C. Marini, A., 2013. TDCS over the left inferior frontal cortex improves speech production in aphasia. Front. Hum. Neurosci. 7.

Marangolo, P., Fiori, V., Campana, S., Calpagnano, M.A., Razzano, C., Caltagirone, C., Marini, A., 2014. Something to talk about: enhancement of linguistic cohesion through tdCS in chronic non fluent aphasia. Neuropsychologia 53, 246-256.

Marini, A., 2012. Characteristics of narrative discourse processing after damage to the right hemisphere. In Seminars in Speech and Language 33. Thieme Medical Publisherspp. 68-78.

Marini, A., Urgesi, C., 2012. Please get to the point! A cortical correlate of linguistic informativeness. J. Cogn. Neurosci. 24, 2211-2222.

Marini, A., Tavano, A., Fabbro, F., 2008. Assessment of linguistic abilities in Italian children with specific language impairment. Neuropsychologia 46, 2816-2823.

Marini, A., Carlomagno, S., Caltagirone, C., Nocentini, U., 2005. The role played by the right hemisphere in the organization of complex textual structures. Brain Lang. 93 (1), 46-54.

Marini, A., Andreetta, S., del Tin, S., Carlomagno, S., 2011a. A multi-level approach to the analysis of narrative language in aphasia. Aphasiology 25, 1372-1392.

Marini, A., Galetto, V., Zampieri, E., Vorano, L., Zettin, M., Carlomagno, S., 2011 b. Narrative language in traumatic brain injury. Neuropsychologia 49, 2904-2910.

Mayer, M., 1969. Frog, where are you? Dial Press, New York.

Mazoyer, B.M., Tzourio, N., Frak, V., Syrota, A., Murayama, N., Levrier, O., Mehler, J., 1993. The cortical representation of speech. J. Cogn. Neurosci. 5 (4), 467-479.

Meadows, J., 1974. The anatomical basis of prosopagnosia. J. Neurol., Neurosurg. Psychiatry 37, 489-501.

Moscovitch, M., 1983. The linguistic and emotional functions of the normal right hemisphere. Cogn. Process. Right Hemisph. 57-82.

Nicholas, L.E., Brookshire, R.H., 1993. A system for scoring main concepts in the discourse of non-brain-damaged and aphasic speakers. Clin. Aphasiology 21, 87-99.

Price, C.J., 2010. The anatomy of language: a review of 100 fMRI studies published in 2009. Ann. New Y. Acad. Sci. 1191 (1), 62-88.

Reilly, J., Losh, M., Bellugi, U., Wulfeck, B., 2004. "Frog, where are you?" Narratives in children with specific language impairment, early focal brain injury, and Williams syndrome. Brain Lang. 88 (2), 229-247.

Reilly, J.S., Bates, E.A., Marchman, V.A., 1998. Narrative discourse in children with early focal brain injury. Brain Lang. 61 (3), 335-375.

Rivers, D.L., Love, R.J., 1980. Language performance on visual processing tasks in right hemisphere lesion cases. Brain Lang. 10 (2), 348-366.

Rogalski, Y., Edmonds, L.A., 2008. Attentive Reading and Constrained Summarisation (ARCS) treatment in primary progressive aphasia: a case study. Aphasiology 22 (7-8), 763-775.

Rosen, H.J., Gorno-Tempini, M.L., Goldman, W.P., Perry, R.J., Schuff, N., Weiner, M., Miller, B.L., 2002. Patterns of brain atrophy in frontotemporal dementia and semantic dementia. Neurology 58, 198-208.

Sherratt, S., 2007. Right brain damage and the verbal expression of emotion: a preliminary investigation. Aphasiology 21 (3-4), 320-339.

Sherratt, S., Bryan, K., 2012. Discourse production after right brain damage: gaining a comprehensive picture using a multi-level processing model. J. Neurolinguist. 25 (4), 213-239.

Troiani, V., Fernández-Seara, M.A., Wang, Z., Detre, J.A., Ash, S., Grossman, M., 2008. Narrative speech production: an fMRI study using continuous arterial spin labeling. Neuroimage 40 (2), 932-939.

Ulatowska, H.K., North, A.J., Macaluso-Haynes, S., 1981. Production of narrative and procedural discourse in aphasia. Brain Lang. 13 (2), 345-371.

Ulatowska, H.K., Allard, L., Chapman, S.B., 1990. Narrative and procedural discourse in aphasia. Discourse ability and brain damage. Springer, New York, pp. 180-198.

Ulatowska, H.K., Freedman-Stern, R., Doyel, A.W., Macaluso-Haynes, S., North, A.J., 1983. Production of narrative discourse in aphasia. Brain Lang. 19 (2), 317-334.

Uryase Sr, D., Duffy, R.J., Liles, B.Z., 1991. Analysis and description of narrative discourse in right-hemisphere-damaged adults: a comparison with neurologically normal and left-hemisphere-damaged aphasic adults. In: Prescott, T.E. (Ed.), Clinical Aphasiology 19. TX: Pro-Ed, Austin, pp. 125-1358.

Williams, G.B., Nestor, P.J., Hodges, J.R., 2005. Neural correlates of semantic and behavioral deficits in frontotemporal dementia. Neuroimage 24 (4), 1042-1051.

Xu, J., Kemeny, S., Park, G., Frattali, C., Braun, A., 2005. Language in context: emergent features of word, sentence, and narrative comprehension. Neuroimage 25 (3), 1002-1015. 